Paidéia, 2003, 12(24), 175-183

\title{
A RELAÇÃO COM O SABER, COM O APRENDER E COM A ESCOLA: UMA ABORDAGEM EM TERMOS DE PROCESSOS EPISTÊMICOS ${ }^{1}$
}

\author{
Maria José Braga Viana ${ }^{2}$ \\ FFCL - Fundação Monsenhor Messias, $M G$
}

\begin{abstract}
RESUMO: $O$ artigo discute contribuições de Bernard Charlot e Jean-Yves Rochex acerca da relação com o saber, com o aprender e com a escola. Os conceitos constitutivos desse quadro teórico encontram-se embrionários; os autores esboçam uma clara distinção entre informação, conhecimento e defendem que os diversos objetos do aprender implicam em diferentes tipos de atividades do sujeito. $O$ conceito de relação com o saber ocupa lugar central na discussão; a noção de relação é entendida como conjunto de significados e espaço de atividades do sujeito, inscritos num tempo. Mobilização, atividade e sentido emergem como noções centrais da relação com o saber e a problemática da mobilização na escola é trabalhada na perspectiva de distintas formas de relação com o saber e aprender. Estabelece-se uma hipótese de que parte importante das condições de possibilidade de sucesso e mobilização escolares, sobretudo em meios populares, é constituída exterior e anteriormente à experiência escolar; como a produção de significados que se atribui à escola e à escolarização produzida no contexto da história das famílias.
\end{abstract}

Palavras-Chave: processos epistemológicos, conhecimento, aprendizagem, escola

\section{THE RELATIONSHIP BETWEEN KNOWLEDGE, TO LEARN AND THE SCHOOL: ONE EPISTEMOLOGICAL PROCESS APPROACH}

\begin{abstract}
This article intends to discuss some contributions Bernard Charlot and Jean-Yves Rochex have given about the relationship with knowledge, learning and school. The authors establish an enlightening distinction between information, knowledge, learning, and defend the idea that the various objects of learning imply different types of subjects' activities. The relationship with the knowledge concept is central in such discussion, with the notion of relationship understood as the grouping of meanings and the space of the subject's activities inscribed at a time. Thus, mobilization, activity and meaning emerge as central notions in the relationship with knowledge, and the problem of mobilization at the school is discussed considering the fact that there are different forms of relationship with the process of learning. It is established the hypothesis that an important part of school mobilization and success possibility is constituted before and outside the experience of the formal school itself. One example is the production of meaning witch is attributed to the formal school and which is, many times, produced in the context of the family.
\end{abstract}

Key-Words: epistemological process, knowledge, learning, school

"A questão da relação com o saber pode ser colocada quando se constata que certos indivíduos, jovens ou adultos, têm desejo de aprender, enquanto outros não manifestam esse mesmo desejo. Uns parecem estar dispostos a aprender algo novo, são apaixonados por este ou por aquele tipo de saber, ou, pelo menos, mostram uma certa disponibilidade para aprender. Outros parecem pouco motivados para aprender, ou para aprender isso ou aquilo, e, às vezes, recusam-se explicitamente a fazê-lo" (Charlot, 2001, p. 15).

\footnotetext{
${ }^{1}$ Artigo recebido para publicação em 09/2002; aceito em 12/2002

${ }^{2}$ Endereço para correspondência: Maria José Braga Viana, Faculdade de Filosofia, Ciências e Letras, Fundação Monsenhor Messias. Rua Alvaro da Silva Lopes $\mathrm{N}^{\circ} 22$ - Parque Roberto Belisario. Pedro Leopoldo MG. CEP. $33.600-000$
} 


\section{Problemática e o Campo de Referências Empíricas}

\section{$O$ ponto de partida dos autores}

Indagações ligadas à problemática do fracasso (e do sucesso) escolar nos meios populares serviram como ponto de partida para as pesquisas empíricas do grupo de pesquisa ESCOL, acima referido, assim como para o surgimento do grupo, e ainda se mantêm como horizonte de elaboração teórica. Essas questões são as seguintes:

Por que será que certos alunos fracassam na escola? Por que será que esse fracasso é mais freqüente entre famílias de categorias sociais populares do que em outras famílias? Mais ainda: por que será que certas crianças dos meios populares alcançam, apesar de tudo, sucesso em seus estudos, como se elas conseguissem esgueirar-se pelos interstícios estatísticos? (Charlot, 2000, p. 9) .

Charlot e sua equipe de pesquisa (2000), entendendo que os parâmetros de inteligibilidade para a clássica problemática do fracasso escolar situam-se num "campo saturado de teorias construídas $e$ opiniões de senso comum" (p. 9), procuram abordála de uma forma nova. Assim, desenvolvem críticas contundentes às abordagens disponíveis, sobretudo às teorias da reprodução $0^{4}$, e propõem novas perspectivas de análise em termos de relação com o saber e com a escola. Contrapondo-se aos modos de entendimento da questão propostos pelas teorias da reprodução, esta abordagem privilegia "as situações, as histórias, as condutas, os discursos", assim como os processos de produção das situações de sucesso e de fracasso escolares, identificados em casos singulares (pressupondo-se que, em sendo sin-

\footnotetext{
${ }^{4}$ As principais críticas às teorias constitutivas do "paradigma da reprodução", formuladas pelo próprio Charlot $(2000,2001)$ e pela equipe ESCOL, acentuam que elas não permitem conhecer as excepcionalidades em termos de sucesso escolar em meios populares, assim como os casos marginais de escolaridades mal sucedidas em meios favorecidos, porque escapa de sua análise a história singular dos alunos. Essas críticas consideram ainda o fato desse paradigma ter sido interpretado "de forma abusiva" em termos de deficiência e de causalidade e, nesse sentido, ter possibilitado a difusão de uma "leitura negativa" do fracasso escolar e dos processos de escolarização nos meios populares.
}

gulares, não deixam de ser sociais). Ou seja, os autores propõem uma "leitura positiva" do fenômeno, "que $e ́$, antes de tudo, uma postura epistemológica e metodológica" (Charlot, 2000, p. 30):

Praticar uma leitura positiva não é apenas, nem fundamentalmente, perceber conhecimentos adquiridos ao lado das carências, é ler de outra maneira o que é lido como falta pela leitura negativa. Assim, ante um aluno que fracassa num aprendizado, uma leitura negativa fala em deficiências, carências, lacunas (...), enquanto que uma leitura positiva se pergunta "o que está ocorrendo", qual a atividade implementada pelo aluno, qual o sentido da situação para ele (...), etc. A leitura positiva busca compreender como se constrói a situação de um aluno que fracassa em um aprendizado e, não, "o que falta" para essa situação ser uma situação de aluno bem sucedido" (Charlot, 2000, p.30).

As pesquisas que foram desenvolvidas pelo grupo, centradas sobre a temática mais geral da relação com o saber (com o aprender e com a escola), tinham como objetivo responder a essas indagações e foram realizadas com jovens, em sua maioria, oriundos das camadas sociais mais desfavorecidas, que frequientavam escolas públicas da periferia de Paris, em níveis que correspondem ao ensino médio e ao segundo ciclo do ensino fundamental $\left(5^{\mathrm{a}}\right.$ à $8^{\mathrm{a}}$ série), no caso brasileiro. Foram comparados resultados obtidos em turmas com alto e baixo desempenho escolar.

Os instrumentos de pesquisa utilizados foram os inventários de saber, acompanhados de entrevistas semidirigidas aprofundadas. Esses inventários, apresentados de forma escrita, constituíram uma espécie de balanço dos saberes que, segundo os autores, no contexto geral daquilo que os jovens aprenderam na vida, fazia mais sentido para eles.

A questão-modelo que orientou a produção desses inventários foi: "Tenho ... anos. Aprendi coisas em casa, na cidade, na escola e em outros lugares. $O$ que para mim é importante em tudo isso? E agora, o que espero?" O que fazia sentido para os jovens naquilo que aprenderam e suas escothas constituem o que interessou aos pesquisadores 
investigar. Esses inventários assumiram as mais variadas formas de textos escritos: de algumas linhas a uma página, relatos longos, acompanhados de argumentações gerais sobre o saber que chegaram a três ou quatro páginas (Charlot, 1996, p. 51).

\section{Uma "ponte" com questões de pesquisa}

Uma curiosidade acerca da temática da escolarização das camadas populares e, mais especificamente, dos casos improváveis de sucesso escolar nesses meios, norteou uma pesquisa (Viana, $1998)^{10}$ em que se procurou investigar condições facilitadoras de permanência no sistema escolar para jovens que, consideradas as características econômicas, sociais e culturais próprias a seu ambiente, não eram destinados ao sucesso escolar. Para tanto, foi obtida a história de escolarização de sete universitários (cinco mulheres e dois homens), através de entrevistas abertas e semi-diretivas com estes jovens e suas famílias, tendo definido sucesso escolar como o acesso ao ensino superior, batizando essa situação de longevidade escolar.

Na construção do objeto de estudo, duas hipóteses iniciais de trabalho foram fortemente inspiradas pelo quadro teórico: De que maneira estavam presentes no processo de construção dessas escolaridades atípicas os fatores ${ }^{5}: 1$ ) os processos familiares (e do filho-aluno) de mobilização escolar; 2 ) os significados atribuídos à escola pela família e pelo filho-aluno e os processos subjetivos de ruptura e descontinuidade, de continuidade e de ambivalências, oriundos das relações intergeracionais produzidas nesses contextos de emancipação social e cultural. Assim, pinçando esses dois traços estruturantes da análise (hipóteses de fatores de sucesso escolar) os casos foram pesquisados e serão utilizados como campo de referências empíricas para a discussão.

\footnotetext{
${ }^{10}$ Pesquisa de doutorado.

5 "fatores" nomeados de parâmetros ou traços estruturantes de análise. Os outros três parâmetros, ou hipóteses preliminares de análise, foram os seguintes: 1) disposiçoes e condutas temporais (pessoais e familiares); 2) grupos de referência para o filho-aluno exteriores ao núcleo familiar e as oportunidades daf decorrentes; 3) modelos socializadores familiares, ou (tipos de presença educativa das famílias (Viana, 1998).
}

\section{A Noção de Relação com o Saber: Dimensões Constitutivas do Conceito}

\section{Distinções preliminares}

É relevante mostrar a diferença que Charlot (2000), reportando-se a Monteil (1985) e Schlanger (1978), estabelece entre informação, conhecimento e saber. " $O$ conhecimento é o resultado de uma experiência pessoal, ligada à atividade de um sujeito provido de qualidades afetivo-cognitivas; como tal é instransmissivel, está sob a primazia da subjetividade" (p. 61). Tanto a informação, quanto o saber, estão sob a primazia da objetividade, podendo, por isso, ser armazenados, estocados, inclusive em um banco de dados. O saber, no entanto, distingue-se da informação, porque traz a marca da apropriação pelo sujeito e, portanto, aproxima-se da noção de conhecimento. Assim, segundo Charlot (2000), "não há saber senão para um sujeito", porque implica em relação consigo mesmo e com os outros, em atividade deste sujeito; e, em segundo, "não há saber em si mesmo" (p.62-3).

Este autor defende que o termo aprender carrega um sentido mais amplo que o saber. Em primeiro lugar, porque muitas coisas e de naturezas diversas podem ser aprendidas, como um saber com o sentido estrito de um conteúdo intelectual, dominando um objeto, uma atividade (aprender a nadar, andar de bicicleta, manusear um aparelho) ou formas relacionais (a convivência em distintos grupos sociais). Daí a importância de não se confundir os diferentes objetos do aprender, que implicam em tipos de atividades do sujeito (relação com o saber enquanto relação epistêmicall ${ }^{\prime \prime}$ Em segundo lugar, o termo aprender é mais amplo também porque implica em considerar, além da dimensão de um sujeito de saber (que se dedica, ou pretende dedicar-se, à busca do saber - um sujeito epistêmico), outras intimamente imbricadas, como a relação de identidade e a social (esta última sendo relação com o saber e com o aprender no contexto de um determinado ambiente social, sob formas e condições preexistentes).

\footnotetext{
11 ). No entanto, mesmo considerando estes diferentes níveis de abrangência, designa-se por "relação com o saber" a "relaçāo com o aprender", qualquer que seja a forma do aprender em questão (Charlot, 2000, p. 86).
} 


\section{$O$ conceito de relação com o saber}

As definições de relação com o saber encontram-se no contexto de um quadro conceitual e teórico ainda embrionário, segundo declaração do próprio autor (Charlot, 2000), com formulações construídas ao longo dos últimos dez anos. Em 1982, o autor assim a definia:

"Chamo relação com o saber o conjunto de imagens, de expectativas e de juízos que concernem ao mesmo tempo ao sentido e à função social do saber e da escola, à disciplina ensinada, à situação de aprendizado e a nós mesmos" (Charlot, 2000, p. 80).

Ausente desta definição está, segundo compreensão mais atual do autor, por um lado, a idéia central de relação e, por outro, o entendimento de que ela ultrapassa os saberes escolares. Hoje, são adotadas as seguintes definições:

"A relação com o saber é a relação com o mundo, com o outro e com ele mesmo, de um sujeito confrontado com a necessidade de aprender. (...) é o conjunto (organizado) das relações que um sujeito mantém com tudo quanto estiver relacionado com 'o aprender' e o saber” (Charlot, 2000, p. 80).

A ênfase do conceito de relação com o saber, num sentido mais geral, está colocada justamente na noção de relação: uma forma de relação com o mundo, que se caracteriza por ser, ao mesmo tempo, simbólica, ativa e temporal, definindo-a, assim nuclearmente como conjunto de significados e espaço de atividades, inscritos num tempo (Charlot, 2000, p. 78).

\section{Mobilização, atividade e sentido: dimensões cen- trais da noção de relação com o saber}

Essas três dimensões da relação com o saber - mobilização, atividade e sentido - se interpenetram no processo de escolarização: "para haver atividade, a criança deve mobilizar-se; para que se mobilize, a situação deve apresentar um significado para ela" (Charlot, 2000, p. 54).

A mobilização coloca ênfase na dinâmica de movimento. "Mobilizar-se é pôr-se em movimento", é acionar recursos; é tanto preliminar à ação, quanto seu primeiro momento. Utilizando-se de uma imagem de situação de guerra, o autor afirma que a mobilização não é a guerra, mas a proximidade da entrada nela (Charlot, 2000, p. 55). O conceito de mobilização aponta, por sua vez, para os conceitos de móbil e de recursos. Entende-se por móbil a razão para agir (distinguindo-se de meta, que está vinculado a resultados esperados). Recursos seriam, então, os trunfos, as forças de diferentes ordens, de que se dispõe e que são atualizados, acionados.

A atividade é definida como "um conjunto de ações propulsionadas por um móbil e que visam a uma meta" (Charlot, 2000, p. 55). Neste ponto, o autor remete-se a Rochex (1995) e a Leontiev (1975) Ele distingue, de forma extremamente sucinta, atividade de prática e de trabalho e defende que estes termos são apenas parcialmente intercambiáveis, porque não significam a mesma coisa. Sem debruçar sobre estas distinções, destaca-se apenas que em atividade enfatiza-se a idéia dos móbiles, para acentuar também a centralidade da noção de sujeito, embora não se negue que a atividade humana se processa num contexto que implica em trabalho e práticas.

A definição de sentido, nuclear nas pesquisas realizadas por Charlot e sua equipe, é inspirada em Leontiev (1975) e Rochex (1995). Propõe-se uma definição que considera três aspectos, dentre os quais destaca-se que é significante, ou, tem sentido, o que produz inteligibilidade sobre algo, o que aclara algo no mundo. $\mathrm{Ou}$, ainda, avançando na análise, "esse sentido é um sentido para alguém que é um sujeito" (Charlot, 2000, p.56). Como conseqüência, tem-se que, necessariamente, introduzir a dimensão do desejo: "pode-se dizer que fazem sentido um ato, um acontecimento, uma situação que se inscrevam nesse nó de desejos que o sujeito é" (p. 67).

\footnotetext{
- Rochex dedica todo o Capítulo II deste seu trabalho a discutir a problemática da atividade, apoiando-se, sobretudo, nos psicólogos soviéticos, Vygotsky e Leontiev. Intitulado "A atividade, unidade de base do desenvolvimento humano" (p. 33-58), este capítulo aborda as seguintes sub-temáticas: 1) do interpsíquico ao intrapsíquico; 2) significações sociais e sentidos pessoais; 3) estrutura da atividade; 4) transformação e desenvolvimento da atividade.
} 
No entanto, propõe-se ainda uma distinção entre sentido enquanto desejabilidade, isto é, que implica em valor, negativo ou positivo, e sentido enquanto significação. Uma ilustração da diferença entre sentido enquanto desejabilidade e significação, segundo o autor, está expressa no fato de que o alpinismo pode ter um significado para mim de uma forma genérica, sem existir um valor, algo vinculado ao desejo. Finalmente, o autor defende, apoiado em reflexões de Rochex (1995), que o sentido não é estático: "algo pode adquirir sentido, perder seu sentido, mudar de sentido" (p. 57).

No que diz respeito à relação da criança e do adolescente com o saber escolar, com o aprender na escola, torna-se nuclear a compreensão das noções de mobilização, sentido e atividade.

Mobilização na Escola e em Relação à Escola: Distintas Formas de Relação com o Saber e com o Aprender

"O problema da relação com a escola não se confunde com a relação com o saber, mas não se pode analisar, na realidade, a questão da relação com a escola, sem levar em conta a relação com o saber, aí incluídas as formas as mais "relacionais" desta relação, como, por exemplo, aquelas que estão em debate quando se analisa os fenômenos da violência escolar" (Rochex, 1995, p. 141).

Dados das pesquisas centradas nos inventários de saber de Charlot e Rochex: ênfase nos processos epistêmicos e significados do aprender

As pesquisas, referidas acima, buscaram identificar a natureza da atividade de aprender para os jovens investigados. Uma das constatações centrais a que esses pesquisadores chegaram é que aprender não passa pelos mesmos processos. $O$ inventário construído com os dados da pesquisa identifica distintas figuras do aprender, conforme relação epistêmica com o saber, ênfase em processos e atividades implicados em cada tipo de aprender. Assim, aprender a nadar, enquanto dominar uma prática, é diferente de aprender sobre a natação, enquanto conjunto de enunciados sobre um saber-objeto; essas duas aprendizagens constituem relações epistêmicas dife- rentes com o saber. Principais figuras do aprender identificadas na pesquisa:

1) Aprender saberes-objetos e objetos-saberes, definidos e diferenciados por Charlot (2000).

"Por objeto-saber, entendo um objeto no qual um saber está incorporado (por exemplo, um livro). Por saber-objeto, entendo o próprio saber, enquanto objetivado, isto é, quando se apresenta como um objeto intelectual, como o referente de um conteúdo de pensamento (a modo da Idéia em Platão)"(p. 75).

2) Aprender uma atividade, ou seja, capacitar-se para utilizar um objeto de forma pertinente, como, por exemplo, um aparelho eletrônico, ou dominar uma prática, como nadar ou andar de bicicleta.

3) Aprender dispositivos relacionais, como dominar uma relação, um aprendizado, como, por exemplo, a iniciar uma relação amorosa ou conviver em ambientes sociais diferentes do seu meio de pertencimento.

Outra constatação central da referida pesquisa é a de que aprender não significa a mesma coisa para todos. As descobertas das diferenças no campo dos significados do aprender têm implicações de peso em termos de apropriação de saberes-objetos e objetos-saberes, e, portanto, nos resultados escolares desses mesmos jovens, pressupondo-se que esses tipos de saber são, nos dias atuais, marcadamente escolares.

Intimamente imbricadas nesse processo, encontram-se relações sociais e de identidade, que implicam em determinadas formas de se engajar no aprender. Charlot (2000) argumenta que:

“(...) qualquer relação com o saber comporta também uma dimensão de identidade: aprender faz sentido por referência à história do sujeito, às suas expectativas, às suas referências, à sua concepção de vida, às suas relações com os outros, à imagem que tem de si e à que quer dar de si "( p. 72).

Por outro lado, a relação com o saber, embora sendo de um sujeito, é também social. Uma situação trabalhada pelos autores é a dos meninos e jo- 
vens das camadas populares que valorizam o aprender, o saber escolar, porque este lhes permite 'se virar' na vida com menos dificuldades que seus pais' . Assim, para alguns alunos investigados, a relação com a escola é marcada pela exterioridade a um saberobjeto, enquanto processo que exige atividades intelectuais específicas, caracterizada mais como profissional do que cultural e cognitiva. A relação com o saber e com o aprender desse grupo de jovens encontra explicação no contexto de sua maneira de lidar com a vida, que é marcada pela busca de construir possibilidades de agir, de ações possíveis no espaço do cotidiano (Charlot, 1996). Para outro grupo de jovens que se encontrava em situações escolares mais favoráveis, o processo epistêmico típico-ideal estava centrado nos aprendizados intelectuais e escolares, construído pela mediação de atividades específicas.

\begin{abstract}
"Aprender é para eles apropriar-se dos objetos de saber, ter acesso a um mundo de saber organizado em disciplinas (...); eles exprimem aprendizados em termos de conteúdos de pensamento descontextualizados, de objetos pensáveis em si mesmos, sem referência direta a um Eu em situação" (Charlot, 1996, p. 59).
\end{abstract}

Rochex (1995), desenvolvendo uma pesquisa distinta, mas extraindo resultados a partir dos dados da mesma investigação anteriormente citada, aprofunda a reflexão no tocante à problemática do sucesso e fracasso escolares, apontando tipos de relação com o saber e aprender que são facilitadores de aprendizagem escolar. No seu quadro teórico são também básicos os conceitos de atividade e de sentido. Os principais temas que investiga são as etapas da escolaridade e seus momentos decisivos, os processos de longa duração que cristalizam estes momentos, as relações com as disciplinas, atividades de aprendizagem e conteúdos.

Neste estudo, Rochex focaliza quatro casos de sucesso escolar e seis de escolarização proble-

\footnotetext{
${ }^{7}$ Essa constatação tem sido reiterada nos estudos que abordam a relação das familias populares com a escola e com a escolarização dos filhos, assim como dos sujeitos oriundos desses meios, considerados individualmente.
}

máticas ${ }^{8}$. Os primeiros estão relacionados com determinados sentidos atribuídos à escolarização; em sua dimensão objetiva, as atividades e conteúdos escolares não se reduzem a significados em termos de abertura de possibilidades de inserção no mercado de trabalho, de melhores condições de vida material, mas, diferentemente, assumem significados neles mesmos. As atividades de aprendizagem são reconhecidas como cognitivas e requerem um trabalho, um investimento pessoal por parte do sujeito.

Por outro lado, casos de dificuldades escolares detectados por este pesquisador mostram a interferência marcante de significados escolares desmobilizadores. O sentido fundamental atribuído por estes jovens à escola e à aprendizagem advém de uma relação utilitária, ao lado da não identificação da sua especificidade e das atividades cognitivas requeridas para obter sucesso (Rochex, 1995). Para eles a escolaridade justifica-se apenas como uma passagem obrigatória para uma boa profissão. $\mathrm{Na}$ escola "não há nada a fazer ou compreender; é suficiente compreender regras"(Rochex, 1995, p. 262). Delphine, um dos casos investigados, uma jovem de 19 anos, tem um projeto profissional; pretende ser professora de educação física e, portanto, quer uma formação universitária, mas isto situa-se no nível do imaginário, apenas em sua dimensão formal, por considerar que os conteúdos escolares não servem para nada.

\section{Ênfase no aprendizado de dispositivos relacionais: uma reflexão a partir do estudo so- bre longevidade escolar em meios populares}

"No, la escuela no sólo les oferecia una evasión de la vida de familia. En la classe del señor Bernard por lo menos, la escuela alimentaba en ellos un hambre más esencial todavía para el niño que para el hombre, que es el hambre de descubrir. (...) sentían por

\footnotetext{
${ }^{R}$ Rochex analisa outras dimensões que não serão consideradas no âmbito deste trabalho. Estas outras dimensões dizem respeito a determinados tipos de relação do adolescente com sua origem social, através da família. Sentidos e relaçōes intersubjetivas e intergeracionais que podem representar uma forte energia e dar suporte para uma forte mobilização escolar pessoal, ou, ao contrário, podem implicar em importantes impedimentos e, portanto, em destinos escolares mal-sucedidos.
} 
primera vez que existían y que eran objeto de la más alta consideración: se los juzgava dignos de descubrir el mundo" (Camus, 1994, p. 128).

Embora a ênfase do modelo de análise adotado por Charlot e Rochex recaia sobre as histórias escolares singulares, sobre os sujeitos das experiências investigadas, esta abordagem não nega a dimensão social que estrutura a relação com o saber porque, por um lado, exprime as condições sociais de existência do indivíduo e, por outro lado, porque "as expectativas face ao futuro e à escola exprimem as relações sociais que "estruturam nossa sociedade" (Charlot, 1996, p. 62).

Assim, partindo do entendimento de que o social estrutura as condições de existência que, por sua vez, se expressam em formas distintas de relação com o saber e com o aprender, os estudos, sobretudo no campo da Sociologia da Educação, têm mostrado que as camadas populares travam com a escola e a escolarização uma relação sempre muito tensa e marcada pela ambigüidade, até pelo fato de estas camadas colocarem na escola fortes expectativas de emancipação social e cultural.

Um dos dados da pesquisa de doutorado ilustra o fenômeno acima mencionado: os significados de uma escolarização prolongada (até a entrada na Universidade) podem estar fortemente centrados em expectativas dessa natureza, especificamente, na busca de aprendizado de dispositivos relacionais; e esses significados podem ser impulsionadores decisivos de mobilização em relação à escola e na escola.

O caso de Júlia, uma das entrevistadas, parece pertinente nesta questão. De origem camponesa, oriunda do meio rural de Minas Gerais, só conseguiu ingressar no ensino superior com 32 anos, num Curso de Geografia da UFMG, quando também saiu da roça. No momento da entrevista, tinha 38 anos. Viveu uma trajetória singular, com experiência de freqüentar a escola regular reduzida, sem pré-escola, cursando as três primeiras séries do ensino fundamental na zona rural, próximo de sua casa, fazendo a partir da $4^{2}$ série e todo o ensino médio através do supletivo, por correspondência postal e daí deu um grande salto para a Universidade. Ela construiu sua caminhada rumo à Universidade de forma auto-determinada, obstinada (Viana, 1998), sendo a escola um instrumento privilegiado de integração na sociedade; e um dos elementos mobilizadores de energia esteve centrado no significado da escolarização como possibilidade de emancipação de suas condições de sociais e culturais de existência; integrar-se na sociedade para ela significava "saber conviver com as pessoas, saber tratar com as pessoas, saber relacionar. (...) Se a pessoa tava conversando, eu não entendia nada (...); sentia assim praticamente isolada"'.

A Universidade, o estudo, o acesso à cultura legítima, aos saberes escolares, representavam para ela poder se igualar, se sentir valorizada, saber conviver, tratar e conversar com pessoas de outros meios sociais. Falas reiteradas sobre a relação entre ser da roça e não se realizar, não se desenvolver constituíram uma tônica de seu discurso e indicam um forte sentimento de isolamento social e de auto-desvalorização. A escola, com todos os benefícios que pode oferecer, era vista como o instrumento privilegiado, senão o único, de ruptura e emancipação das origens. Via escolarização, evitava reproduzir a situação de "gente da roça", cujo significado era o da inferioridade, da humilhação. A Universidade em particular, constituía a porta de entrada principal para um universo cultural distante do seu meio de pertencimento, para $o$ acesso a outros grupos de referência, com os quais ela desejava conviver, conversar, tratar, igualar-se.

Utilizando a teoria de Charlot e Rochex como subsídio de interpretação, tem-se como hipótese que o aprendizado de dispositivos relacionais constituía para Júlia a fonte de uma energia vital de mobilização em relação à escola, à Universidade e também o fôlego para sua sobrevivência no interior da mesma Universidade.

\section{Considerações Finais}

Das análises precedentes, no quadro da teoria da relação com o saber (Charlot, 1996, 2000, 2001; Rochex, 1995; Charlot \& Rochex, 1996), duas implicações de natureza pedagógica são extraídas, pontuando reflexões que parecem apropriadas: 
1- Uma pedagogia que crie possibilidade de sucesso escolar em meios populares ou uma crítica às práticas instrucionäis tradicionais.

Essa teoria fornece elementos para a formulação de uma crítica às práticas da gestão da aprendizagem que se processam tradicionalmente na escola, que se pautam pela transmissão de conteúdos, e assim, a título de anúncio, aproximar essa crítica da que é dirigida ao instrucionismo que defende a tese da (re)construção do conhecimento" .

Inspirada em Rochex (1995), essa reflexão se relaciona com a questão das possibilidades, dificuldades ou impedimentos de sucesso escolar, sobretudo em meios populares. Este autor defende que, se uma parte importante das condições, objetivas e subjetivas, de sucesso e mobilização escolares (ou, ao contrário, aquilo que lhe faz obstáculo) é constituída anterior e exteriormente à experiência escolar ${ }^{10}, 0$ funcionamento da escola pode contribuir de maneira também importante ao processo de produção dessas condições.

Colocada a contribuição da escola para a produção do sucesso ou do fracasso escolares, e mantendo o modelo de análise que o orienta, o autor levanta hipóteses que vão assinalar a interface entre aprendizagem e ensino e que são caracteristicamente construtivistas, uma vez que dão ênfase à dimensão cognitiva da experiência escolar; o argumento é, então, a favor de se levar os alunos, crianças e jovens, a reconhecerem os saberes e conteúdos culturais como produtos de um trabalho de pensamento, como atividade cognitiva do sujeito. Diferente é tratálos (os saberes e conteúdos culturais) como objetos ou elementos de um capital que requer mais a memória, que se circunscrevem na ordem do ter, da posse/não-posse. É abordá-los em termos dos possuidores e dos despossuídos de saber, termos pensa-

\footnotetext{
${ }^{9}$ A esse respeito ver Demo: Educação \& Conhecimento - Relação necessária, insuficiente e controversa (Petrópolis, Vozes, 2000); Educar pela pesquisa (Campinas, Autores Associados, 1996); Conhecer \& Aprender - Sabedoria dos limites e desafios (Porto Alegre, Artmed, 2000); Saber pensar (São Paulo, Cortez/ Instituto Paulo Freire, 2000).

${ }^{10}$ Dentre as condiçðes que possibilitam ou dificultam o sucesso escolar que são produzidas exterior e anteriormente da escola estão "a história e us práticas familiares, as competências, procedimentos e disposições cognitivas que aí se constroem, as continuidades $e$ contradiçóes que se estabelecem no seio dos processos identificatórios ligadas às relações entre gerações" (Rochex, 1995, p. 282).
}

dos como dicotômicos, sem relações de continuidade entre si. Assim, Rochex defende a necessidade de se colocar no centro das situações de aprendizagem a atividade do aluno, ao invés dos discursos do professor (do instrucionismo).

No contexto de uma relação reflexiva com os saberes, com o conhecimento e com a aprendizagem, pressupondo que "a aprendizagem jamais é linear" (p. 286), o autor defende que o ensino deve se fundar sobre a pesquisa. Assim, um fragmento de sua argumentação diz:

\begin{abstract}
“(...) a interrogação crítica sobre as formas consagradas e freqüentemente coisificadas da cultura escolar e de seus modos de transmissão e de exercício pode permitir criar situações de aprendizagem, onde os alunos possam (re)estabelecer uma relação viva com os saberes, com as teorias e com as obras, $\mathrm{e}$ dar, ou restaurar, assim, um sentido para o aprender, e não somente para a acumulação de saberes-objetos, diplomas ou anos de estudos" (Rochex, 1995, p. 288).
\end{abstract}

2- A pedagogia e a dimensão identitária do aprender

A segunda implicação de natureza pedagógica, que se extrai especificamente de Charlot (2000), vincula-se à tese de que "não há sujeito de saber $e$ não há saber, senão em uma certa relação com o mundo"(p. 63). Se o saber é relação, o processo que leva a adotar uma relação de saber com o mundo deve ser objeto de uma educação intelectual, e não a acumulação de conteúdos; se esse não é puramente cognitivo ou didático, mas também identitário, deve considerar que a escolarização, sobretudo a prolongada e para as camadas populares, implica em emancipação social e cultural, em distanciamento das origens, com ou sem rupturas no plano simbólico; "implica sempre a renúncia, provisória ou profunda, de outras formas de relação com o mundo, consigo e com os outros" (p. 64).

Colocada a questão no contexto específico das condições de vida das camadas populares, de seu universo de socialização, o problema da educação em geral e da escola em particular devem se voltar para saber como atualizar o que é dado ao homem 
apenas potencialmente, ou seja, cuidar das estratégias facilitadoras, para essas camadas, de acesso às formas mais elaboradas de atividade intelectual; compreender qual o tipo de relação com o mundo e com o saber essa criança e esse jovem precisam e podem construir com a ajuda da escola.

Esses estudos apontam, em suma, para a possibilidade de se pensar uma pedagogia que permita descobrir outra forma de relação com o mundo distinta da construída no dia-a-dia pelas famílias populares, que considere as dificuldades específicas enfrentadas para terem sucesso na escola (Charlot, 2000).

\section{Referências Bibliográficas}

Camus, A.(1994). El primer hombre. Barcelona: Tusquets Editores.

Charlot, B. (1996). Relação com o saber e com a escola entre estudantes de periferia. Cadernos de Pesquisa. São Paulo, n. 97, p. 47-63.

Charlot, B. (2000). Da relação com o saber Elementos para uma teoria. Porto Alegre: Editora Artmed.

Charlot, B. (2001). Os jovens e o saber-Perspectivas mundiais. Porto Alegre: Editora Artmed.

Charlot, B. \& Rochex, J.Y. (1996). Dynamiques familiales et expérience scolaire. Lien Social et Politiques (pp. 137-151). Canadá.

Leontiev (1975/1984). Activité, conscience, personnalité. Moscou: Editions du Progrès

Monteil, J.M. (1985). Dynamique sociale et systèmes de formation. Paris: Éditions Universitaires.

Rochex, J.Y. (1995). Le sens de l'expérience scolaire: entre activité et subjectivité. $\mathrm{Pa}-$ ris: Presses Universitaires de France.

Schlanger, J. (1978). Une théorie du savoir. Paris: Vrin

Viana, M.J.B. (1998). Longevidade escolar em famílias de camadas populares - Algumas condições de possibilidade. Tese de Doutorado, Universidade Federal de Minas Gerais, Belo Horizonte. 
